\title{
Disk-Diffusion Testing Is an Inappropriate Screening Tool for Cephalosporin-Resistant Gonorrhoea Strains in Clinical Practice in China
}

This article was published in the following Dove Press journal: Infection and Drug Resistance

\begin{abstract}
Yan Han, ${ }^{1,2}$ Yue-Ping Yin, (D) ${ }^{1,2}$ Wen-Qi Xu, ${ }^{1,2}$ Xiao-Yu Zhu, ${ }^{1,2}$ Shao-Chun Chen, (iD) ${ }^{1,2}$ XiuQin Dai, ${ }^{1,2}$ Li-Gang Yang, ${ }^{3,4}$ BangYong Zhu, ${ }^{5} \mathrm{Na}$ Zhong, ${ }^{6}$ Wen-Ling Cao, Xiao-Hui Zhang, ${ }^{3,4}$ Zhi-Zhou Wu, ${ }^{8}$ Liu-Feng Yuan, ${ }^{9}$ Zhong-jie Zheng, ${ }^{10}$ Jun Liu, (iD) "Xiang-Sheng Chen (iD) 1,2

'Institute of Dermatology, Chinese Academy of Medical Sciences and Peking Union Medical College, Nanjing, Jiangsu, People's Republic of China; ${ }^{2}$ National Center for STD Control, Chinese Center for Disease Control and Prevention, Nanjing, Jiangsu, People's Republic of China; ${ }^{3}$ Dermatology Hospital, Southern Medical University, Guangzhou, Guangdong, People's Republic of China; ${ }^{4}$ Guangdong Provincial Dermatology Hospital, Guangzhou, Guangdong, People's Republic of China; ${ }^{5}$ Institute of Dermatology, Nanning, Guangxi Autonomous Region, People's Republic of China; ${ }^{6}$ Hainan Provincial Center for STD/Skin Disease Control and Prevention, Haikou, Hainan, People's Republic of China; ${ }^{7}$ Guangzhou Institute of Dermatology, Guangzhou, Guangdong, People's Republic of China; ${ }^{8}$ Jiangmen Dermatology Hospital, Jiangmen, Guangdong, People's Republic of China; 'Beijing Ditan Hospital Capital Medical University, Beijing, People's Republic of China; ${ }^{10}$ Tianjin Center for Disease Control and Prevention, Tianjin, People's Republic of China;

"'Harvard Medical School, Boston, MA, USA
\end{abstract}

Correspondence: Yue-Ping Yin Institute of Dermatology, Chinese Academy of Medical Sciences and Peking Union Medical College, I 2 Jiangwangmiao Street, Nanjing 210042, People's Republic of China

Tel/Fax +86258 5478024

Email yinyp@ncstdlc.org
Purpose: Injectable ceftriaxone and oral cefixime are the last agents effective against Neisseria gonorrhoeae. In vitro antimicrobial-susceptibility testing (AST) is done to identify the most efficacious antibiotic needed to combat the infection in that particular individual. The objective of this study was to evaluate whether Kirby-Bauer (KB) disk-diffusion tests can detect $N$. gonorrhoeae isolates that have decreased susceptibility to ceftriaxone and cefixime for appropriate clinical management.

Methods: A total of 1,633 consecutive clinical isolates of $N$. gonorrhoeae were collected from January 1, 2013 to December 31, 2017 from seven dermatology clinics located in five provinces in China. Consistency between $\mathrm{KB}$ disk-diffusion tests and the agar-dilution method, as well as sensitivity of the $\mathrm{KB}$ test for detecting $N$. gonorrhoeae isolates with decreased susceptibility to ceftriaxone and cefixime, were determined using 1,306 clinical isolates that had been recovered to complete agar-dilution AST.

Results: The prevalence of isolates with decreased susceptibility to ceftriaxone and cefixime was $12.1 \%$ (198 of 1,633) and 12.7\% (208 of 1,633), respectively, using KB disk-diffusion tests. The prevalence of isolates with decreased susceptibility was 9.9\% (129 of 1,306) for ceftriaxone and 9.9\% (129 of 1,305) for cefixime using agar-dilution AST. The categorical agreement of these two methods was $80.9 \%$ for both ceftriaxone and cefixime. Compared to agar-dilution AST, the sensitivity of the KB test for detecting $N$. gonorrhoeae isolates with decreased susceptibility was $22.5 \%$ (29 of 129 ) for ceftriaxone and $29.5 \%$ (38 of 129) for cefixime, and its specificity $87.3 \%(1,028$ of 1,177$)$ for ceftriaxone and $86.7 \%(1,018$ of 1,176) for cefixime.

Conclusion: Although KB tests are easy to carry out in clinical practice, their ability to detect cephalosporin-resistant gonorrhoea strains is limited. This method is not an appropriate selection for screening cephalosporin-resistant gonorrhoea strains in clinical practice in China.

Keywords: Neisseria gonorrhoeae, Kirby-Bauer disk-diffusion tests, agar-dilution method, susceptibility, screen

\section{Introduction}

Gonorrhea remains one of the most common sexually transmitted diseases (STDs) in the world. ${ }^{1}$ Untreated gonorrhea can result in sequelae including chronic pelvic pain, pelvic inflammatory disease, ectopic pregnancy, ${ }^{2}$ infertility in women, ${ }^{3}$ and increasing the risk of infection with HIV. ${ }^{4}$ Since an effective vaccine for gonorrhea is not yet available, timely diagnosis and effective treatment with antimicrobials continue to be the mainstay of disease control. However, antimicrobial resistance 
has emerged for each of the antibiotics recommended as first-line therapies following their introduction to clinical practice. $^{5}$ Recently, extended-spectrum cephalosporins (ESCs), such as injectable ceftriaxone and oral cefixime, are the last agents effective against Neisseria gonorrhoeae. However, the proportion of $N$. gonorrhoeae isolates with decreased susceptibility to ceftriaxone $e^{6,8}$ and the reported number of clinical failures following treatment with these $\mathrm{ESCs}^{9,12}$ has increased over the past decade. If the susceptibility of $N$. gonorrhoeae isolates to ESCs is uncertain, this can lead to therapeutic failures or overtreatment. ${ }^{13}$ Therefore, timely differentiation between ESC-resistant and -susceptible strains is very important for appropriate patient management.

In vitro antimicrobial-susceptibility testing (AST) is used to determine the response of microorganisms to antimicrobial agents to guide clinicians in predicting an in vivo response to antimicrobial therapy. There are several AST methods available for $N$. gonorrhoeae. Methods recommended by the Clinical and Laboratory Standards Institute ${ }^{14}$ include agar dilution and E-test techniques that determine the minimum inhibitory concentration (MIC) of antimicrobials and the disk-diffusion method. The agar-dilution method is recommended as the global gold standard for antimicrobialresistance surveillance of $N$. gonorrhoeae at present. However, conventional agar-dilution methods are laborintensive, require a lot of glassware, and excessive pipetting adds to a larger error margin. Multiple dilutions can cause further errors, and change of personnel will alter the way drugs are diluted. Furthermore, it is difficult to maintain the confluence of culture that needs to be uniform in all experiments. However, the biggest issue is the cost, because these experiments are usually repeated two or three times in order to have conclusive results. The time required for agar dilution can result in a significant delay in the administration of an effective drug. ${ }^{15}$ The E-test is an impervious carrier with a continuous gradient of antimicrobial agent applied to one side of the strip. The test is performed in the same manner as the disk-diffusion test. It determines the MIC of antimicrobial agents; however, this method currently has restricted clinical utility in China, due to its high cost. In clinical microbiology laboratories, the disk-diffusion method described by Bauer et al in $1966^{16}$ is still an affordable, accurate, reliable, and highly standardized AST method for guiding clinical management, with the advantages of low consumable costs and flexible drug testing for many microbial infections. Most clinical laboratories in China can carry out the Kirby-Bauer (KB) test for N. gonorrhoeae, and the proportion of $N$. gonorrhoeae isolates with decreased susceptibility to ceftriaxone is much higher than in other countries. ${ }^{13}$ Therefore, we attempted to explore the utility of the $\mathrm{KB}$ test as a screening test for immediate detection of $N$. gonorrhoeae isolates that have decreased susceptibility to ceftriaxone and cefixime for guiding appropriate clinical management in China. However, the accuracy of the diskdiffusion method to detect gonococcal strains with decreased susceptibility is still controversial, for the number of ESCresistant isolates has been extremely small in published studies. ${ }^{17,18}$ The objective of this study was to evaluate whether the disk-diffusion technique can offer timely detection of cephalosporin-resistant strains for appropriate clinical management by using approximately $10 \%$ of strains with decreased susceptibility to ceftriaxone (129 of 1306) and cefixime (129 of 1,305) from the China Gonorrhoeae Resistance Surveillance Program (GRSP).

\section{Methods}

\section{$N$. gonorrhoeae Isolates}

A total of 1,633 consecutive and nonrepetitive clinical isolates of $N$. gonorrhoeae were collected from January 1, 2013 to December 31, 2017 from seven dermatology clinics in five different provinces (Tianjin, Beijing, Guangdong, Guangxi, and Hainan). These samples were part of the GRSP, and had been saved for use in the present study. Ethics approval for the study was obtained from the Medical Ethics Committee at the Institute of Dermatology, Chinese Academy of Medical Sciences and Peking Union Medical College (approval 2014-LS-026). Methods used for isolation and identification of $N$. gonorrheae have been described previously. ${ }^{13}$

\section{KB Disk-Diffusion Tests}

AST was performed by the $\mathrm{KB}$ disk-diffusion technique using a GC agar base (Oxoid, Basingstoke, UK) with 1\% BBL IsoVitalex Enrichment (BD Diagnostics, Franklin Lakes, NJ, USA) with following concentration disks (Oxoid) of ceftriaxone $30 \mu \mathrm{g}$ and cefixime $5 \mu \mathrm{g}$. The results were interpreted by measuring inhibition-zone diameters and categorizing as susceptible and insusceptible in accordance with the Clinical and Laboratory Standards Institute. For ceftriaxone, we categorized inhibition-zone diameters as susceptible at $\geq 35 \mathrm{~mm}$ and insusceptible at $<35 \mathrm{~mm}$. For cefixime, we categorized inhibition-zone diameters as susceptible at $\geq 31 \mathrm{~mm}$ ) and insusceptible at $<31 \mathrm{~mm}$. This work was 
carried out after timely isolation and purification of the collected strains.

\section{Agar-Dilution AST}

Agar-dilution AST was conducted at the central STD laboratories of the participating provinces around December every year according to WHO recommendations. A detailed procedure for assessing MIC for ceftriaxone was described in our previous study. ${ }^{7}$ Concentrations of cefixime were $0.008,0.015,0.03,0.06,0.125,0.25,0.5$, 1.0 , and $2.0 \mathrm{mg} / \mathrm{L}$. MIC-interpretive criteria were in accordance with the WHO guideline, which defines decreased susceptibility for ceftriaxone as MIC $\geq 0.125 \mathrm{mg} / \mathrm{L}$ and cefixime as $\mathrm{MIC} \geq 0.25 \mathrm{mg} / \mathrm{L}$.

\section{Control Strains}

$N$. gonorrhoeae ATCC 49,226 and WHO reference strains $\mathrm{G}, \mathrm{K} \mathrm{J}, \mathrm{P}$, and $\mathrm{L}$ were used as controls for $\mathrm{KB}$ diskdiffusion and agar-dilution MIC testing. All agar-dilution MIC results for control strains were within the \pm 1 dilution factor. The reproducibility of control strains tested for the KB disk-diffusion test was $>95 \%$. For quality assurance, all the central STD laboratories participated in the external quality-assurance program for agar-dilution MIC testing of the WHO Western Pacific GASP through the National STD Reference Laboratory in Nanjing, China. Results showed $100 \%$ agreement with the reference laboratory results from 2013 to 2017.

\section{Statistical Analysis}

All data analysis was performed using SPSS version 22.0 (IBM, Armonk, NY, USA) for descriptive and inferential analyses. $\mathrm{MIC}_{50}$ and $\mathrm{MIC}_{90}$ of the tested clinical isolates were determined. Pearson's correlation coefficient ( $r$-values) was generated for each cephalosporin agent indexed by susceptibility testing. A correlation coefficient $\geq 0.8$ was considered acceptable. Categorical definitions of susceptible and insusceptible were assigned based on the MICs and using the Clinical and Laboratory Standards Institute-defined interpretive criteria. ${ }^{19}$ The performance of the KB disk-diffusion test was determined by categorical agreement and minor error, which were compared with those of the agar method. The results of $N$. gonorrhoeae for ceftriaxone and cefixime susceptibility by agar dilution AST and the KB disk-diffusion test are only "susceptible" and "insusceptible", so in this study we only calculated minor error. Categorical agreement is the agreement of the sensitivity to ceftriaxone and cefixime between KB disk-diffusion test and agar dilution. Minor error indicates the test result by either agar-dilution AST being interpreted as resistant or susceptible and a KB-test result of intermediate, or agar-dilution AST result of intermediate and KB-test result of resistant or susceptible. Acceptable performance rates were taken as $\geq 90 \%$ for categorical agreement and $\leq 7 \%$ for minor error. ${ }^{20}$ Consistency of sensitivity to ceftriaxone and cefixime between KB diskdiffusion test and agar dilution was compared using McNemar's $\chi^{2}$ test, yielding $P>0.05$, which indicated no significant difference.

\section{Results}

A total of 1,633 gonococcus samples in this study were isolated from 1,526 men (93.4\%) and 107 women (6.6\%). The average age of participants was $33.5 \pm 11.0$ years. Isolates were predominantly from the urethra in men $(1,505$ of $1,526,98.62 \%)$ and the cervix in women (107 of $107,100 \%)$. The recovery rate of collected $N$. gonorrhoeae strains was $80 \%$ (1306 of 1633). All recovered strains $(1,306)$ had had agar-dilution tests for ceftriaxone, while one was missed for cefixime.

Inhibition-zone diameters on KB tests for the clinical isolates were $20-60 \mathrm{~mm}$ and $16-56 \mathrm{~mm}$ for ceftriaxone and cefixime, respectively. The prevalence of isolates with decreased susceptibility to ceftriaxone and cefixime was $12.1 \%$ (198 of 1,633) and $12.7 \%$ (208 of 1,633), respectivelyon $\mathrm{KB}$ tests. MICs for agar-dilution testing of clinical isolates were $0.008-1 \mu \mathrm{g} / \mathrm{mL}$ and $0.008-2 \mu \mathrm{g} / \mathrm{mL}$ for ceftriaxone and cefixime, respectively. Geometric mean ceftriaxone and cefixime MICs were $0.025 \mu \mathrm{g} / \mathrm{mL}(95 \%$ CI $0.023-0.026 \mu \mathrm{g} / \mathrm{mL})$ and $0.037 \mu \mathrm{g} / \mathrm{mL}$ (95\% CI $0 .-$ $035-0.040 \mu \mathrm{g} / \mathrm{mL})$. $\mathrm{MIC}_{50}$ and $\mathrm{MIC}_{90}$ were 0.03 and 0.06 for ceftriaxone and 0.03 and 0.12 for cefixime, respectively. The prevalence of isolates with decreased susceptibility was $9.9 \%$ (129 of 1,306) for ceftriaxone and $9.9 \%(129$ of 1,305$)$ for cefixime.

Consistency between the two methods was determined using 1,306 clinical isolates, which had been recovered to complete agar-dilution AST. The categorical agreement of these two methods was $53.6 \%-98.9 \%$ for ceftriaxone and $67.1 \%-96.6 \%$ for cefixime among seven sites, with total agreement reaching $80.9 \%$ for the two antibiotics, and minor error for KB testing was $19.1 \%$ (249 of 1,306) and $19.1 \%(249$ of 1,305$)$ for the two antibiotics, respectively. When comparing the consistency of sensitivity of ceftriaxone and cefixime between KB testing and agar dilution, there were no linear relationships between the methods for the two antibiotics (Tables 1 and 2). Pearson's correlation 
Table I Comparison of Agar-Dilution Method and KB Test for Ceftriaxone

\begin{tabular}{|c|c|c|c|c|c|c|c|c|c|c|c|c|c|c|c|c|c|c|c|}
\hline \multirow[t]{2}{*}{ MIC $(\mu \mathrm{g} / \mathrm{mL})$} & \multicolumn{19}{|c|}{ Diameters of Inhibition Zone by KB Test (mm) } \\
\hline & 20 & 21 & 22 & 23 & 24 & 25 & 26 & 27 & 28 & 29 & 30 & 31 & 32 & 33 & 34 & 35 & 36 & 37 & 38 \\
\hline $\begin{array}{l}0.008 \\
0.016 \\
0.031 \\
0.062\end{array}$ & I & 1 & I & $\begin{array}{l}1 \\
1 \\
1\end{array}$ & I & $\begin{array}{l}2 \\
1 \\
4\end{array}$ & $\begin{array}{l}1 \\
1 \\
1 \\
2\end{array}$ & $\begin{array}{l}3 \\
1\end{array}$ & $\begin{array}{l}6 \\
2 \\
3 \\
2\end{array}$ & $\begin{array}{l}4 \\
1 \\
3\end{array}$ & $\begin{array}{l}11 \\
3 \\
10 \\
8\end{array}$ & $\begin{array}{l}7 \\
3 \\
1\end{array}$ & $\begin{array}{l}7 \\
5 \\
5 \\
8\end{array}$ & $\begin{array}{l}8 \\
3 \\
3 \\
4\end{array}$ & $\begin{array}{l}8 \\
1 \\
4 \\
6\end{array}$ & $\begin{array}{l}26 \\
18 \\
27 \\
39\end{array}$ & $\begin{array}{l}21 \\
18 \\
20 \\
19\end{array}$ & $\begin{array}{l}15 \\
7 \\
9 \\
10\end{array}$ & $\begin{array}{l}21 \\
25 \\
21 \\
17\end{array}$ \\
\hline $\begin{array}{l}0.125 \\
0.250 \\
0.500 \\
1.000\end{array}$ & & & & $\mathbf{I}$ & & & $\mathbf{I}$ & $\mathbf{I}$ & & & $\begin{array}{l}8 \\
1 \\
1\end{array}$ & $\begin{array}{l}2 \\
1 \\
1\end{array}$ & 2 & I & $\begin{array}{l}6 \\
1 \\
1\end{array}$ & $\begin{array}{l}12 \\
5 \\
4\end{array}$ & $\begin{array}{l}5 \\
2 \\
1 \\
\end{array}$ & $\begin{array}{l}2 \\
2\end{array}$ & $\begin{array}{l}7 \\
2 \\
2\end{array}$ \\
\hline Total & I & I & I & 4 & I & 7 & 6 & 5 & 13 & 8 & 42 & 15 & 27 & 20 & 27 & 131 & 86 & 45 & 95 \\
\hline
\end{tabular}

Notes: Each number in bold type represents the number of isolates with the same susceptibility on the agar-dilution method and the KB test for ceftriaxone (Pearson's correlation coefficient $-r=0.21$ ). All test results of $N$. gonorrhoeae for ceftriaxone by the agar-dilution AST method and the KB test interpreted as insusceptible or usceptible are marked in bold.

Table 2 Comparison of Agar-Dilution Method and KB Test for Cefixime

\begin{tabular}{|c|c|c|c|c|c|c|c|c|c|c|c|c|c|c|c|c|c|c|}
\hline \multirow[t]{2}{*}{ MIC $(\mu \mathrm{g} / \mathrm{mL})$} & \multicolumn{18}{|c|}{ Diameters of Inhibition Zone by KB Test ( $\mathrm{mm})$} \\
\hline & 16 & 17 & 19 & 20 & 21 & 22 & 23 & 24 & 25 & 26 & 27 & 28 & 29 & 30 & 31 & 32 & 33 & 34 \\
\hline $\begin{array}{l}0.008 \\
0.016 \\
0.031 \\
0.063 \\
0.125 \\
\end{array}$ & & $\mathrm{I}$ & $\begin{array}{l}1 \\
1\end{array}$ & $\begin{array}{l}2 \\
2\end{array}$ & I & $\mathrm{I}$ & $\begin{array}{l}1 \\
1\end{array}$ & 2 & $\begin{array}{l}2 \\
5 \\
3 \\
2 \\
3 \\
\end{array}$ & $\begin{array}{l}1 \\
1 \\
3 \\
4 \\
\end{array}$ & $\begin{array}{l}2 \\
1 \\
2 \\
2 \\
5 \\
\end{array}$ & $\begin{array}{l}9 \\
3 \\
5 \\
3 \\
8 \\
\end{array}$ & $\begin{array}{l}4 \\
4 \\
6 \\
2 \\
5 \\
\end{array}$ & $\begin{array}{l}12 \\
11 \\
12 \\
12 \\
11\end{array}$ & $\begin{array}{l}8 \\
12 \\
13 \\
18 \\
9 \\
\end{array}$ & $\begin{array}{l}15 \\
11 \\
17 \\
15 \\
6\end{array}$ & $\begin{array}{l}6 \\
6 \\
13 \\
14 \\
6 \\
\end{array}$ & $\begin{array}{l}9 \\
7 \\
8 \\
10 \\
17 \\
\end{array}$ \\
\hline $\begin{array}{l}0.250 \\
0.500 \\
1.000 \\
2.000\end{array}$ & I & & & $\mathbf{I}$ & & $\begin{array}{l}2 \\
1 \\
1\end{array}$ & $\begin{array}{l}\text { I } \\
\text { I }\end{array}$ & $\begin{array}{l}3 \\
1\end{array}$ & $\begin{array}{l}\text { I } \\
\text { I } \\
\text { I }\end{array}$ & $\begin{array}{l}2 \\
1 \\
1\end{array}$ & $\begin{array}{l}\text { I } \\
\text { I }\end{array}$ & I & $\begin{array}{l}1 \\
I\end{array}$ & $\begin{array}{l}7 \\
5 \\
1\end{array}$ & $\begin{array}{l}8 \\
7 \\
1 \\
2\end{array}$ & $\begin{array}{l}7 \\
5 \\
1 \\
1\end{array}$ & $\begin{array}{l}3 \\
5 \\
1\end{array}$ & $\begin{array}{l}2 \\
3\end{array}$ \\
\hline Total & $\mathrm{I}$ & $\mathrm{I}$ & 2 & 5 & I & 6 & 4 & 7 & 18 & 13 & 14 & 30 & 23 & 71 & 78 & 78 & 54 & 56 \\
\hline
\end{tabular}

Notes: Each number in bold type represents the number of isolates with the same susceptibility on the agar-dilution method and the KB test for cefixime (Pearson's correlation coefficient $-r=0.2 \mathrm{I}$ ). All test results of $N$. gonorrhoeae for cefixime by the agardilution AST method and the KB test interpreted as insusceptible or susceptible are marked in bold.

coefficients between $\mathrm{KB}$ tests and agar dilution were -0.118 and -0.205 , respectively, for ceftriaxone and cefixime. McNemar $\chi^{2}$ tests for the insusceptible category between the two tests yielded highly significant results for ceftriaxone $\left(\chi^{2}=9.25, P=0.002\right)$ and cefixime $\left(\chi^{2}=17.49, P=0\right)$.

There were $129 \mathrm{~N}$. gonorrhoeae isolates were interpreted as non-susceptible by the agar dilution method for ceftriaxone and cefixime. A total of 100 isolates (100 of $129,77.5 \%$ ) were non-susceptible on agar dilution, but susceptible on KB-test sensitivity for ceftriaxone and 91 isolates ( 91 of $129,70.5 \%$ ) for cefixime.KB-test sensitivity in detecting $N$. gonorrhoeae isolates with decreased susceptibility was $22.5 \%$ (29 of 129) for ceftriaxone and $29.5 \%$ (38 of 129) for cefixime, with specificity of $87.3 \%(1,028$ of 1,177$)$ for ceftriaxone and $86.7 \%(1,018$ of 1,176$)$ for cefixime compared to agar-dilution AST.

\section{Discussion}

In this study, we evaluated whether the disk-diffusion technique can detect gonorrhea isolates with decreased susceptibility to ceftriaxone and cefixime in a timely manner for appropriate clinical management, using the strains from seven clinical sites in the GRSP in China. The disk-diffusion test is less labor-intensive and easier to carry out than the AST method, and suitable for clinical tests to guide clinical management for many microbial infections. We were able to perform $\mathrm{KB}$ tests for all $N$. gonorrhoeae strains that had been successfully isolated and cultured in every site included in our study. The proportion of analyzable isolates from this method (1,633 of 1,633) was higher than the agar-dilution method $(1,306$ of 1,633). Agar dilution for the determination of MIC is the gold standard for antimicrobial-resistance surveillance and widely used in global $N$. gonorrhoeae antibiotic resistance-monitoring programs; ${ }^{21,23}$ however, it requires a heavier workload and recovery of isolates from deep-freezer temperatures $\left(-70^{\circ} \mathrm{C}\right)$ or liquid nitrogen for batch tests. ${ }^{19}$ Therefore, the diskdiffusion test is more practical than the agar-dilution method for clinical management to use on a large scale.

In the clinical setting, physicians can obtain the results from disk-diffusion tests in 3 days. In China, most clinicians would immediately prescribe antibiotics for patients diagnosed with gonococcal infection by smear microscopy. They 


\begin{tabular}{|c|c|c|c|c|c|c|c|c|c|c|c|c|c|c|c|c|c|c|c|c|}
\hline & & & & & & & & & & & & & & & & & & & & Total \\
\hline 39 & 40 & 41 & 42 & 43 & 44 & 45 & 46 & 47 & 48 & 49 & 50 & 51 & 52 & 53 & 54 & 55 & 56 & 58 & 60 & \\
\hline $\begin{array}{l}16 \\
6 \\
13 \\
10\end{array}$ & $\begin{array}{l}67 \\
35 \\
57 \\
49\end{array}$ & $\begin{array}{l}19 \\
5 \\
8 \\
7\end{array}$ & $\begin{array}{l}53 \\
17 \\
24 \\
16\end{array}$ & $\begin{array}{l}11 \\
5 \\
10 \\
3\end{array}$ & $\begin{array}{l}19 \\
13 \\
14 \\
10\end{array}$ & $\begin{array}{l}20 \\
12 \\
23 \\
15\end{array}$ & $\begin{array}{l}17 \\
4 \\
14 \\
6\end{array}$ & $\begin{array}{l}4 \\
2 \\
1 \\
1\end{array}$ & $\begin{array}{l}15 \\
4 \\
5 \\
7\end{array}$ & $\begin{array}{l}3 \\
1\end{array}$ & $\begin{array}{l}24 \\
5 \\
10 \\
4\end{array}$ & $\begin{array}{l}3 \\
1\end{array}$ & $\begin{array}{l}3 \\
1 \\
2\end{array}$ & I & $\begin{array}{l}2 \\
1\end{array}$ & $\begin{array}{l}3 \\
1 \\
4 \\
1\end{array}$ & $\begin{array}{l}4 \\
1\end{array}$ & $\begin{array}{l}\text { I } \\
\text { I }\end{array}$ & I & $\begin{array}{l}426 \\
198 \\
298 \\
255\end{array}$ \\
\hline 5 & $\begin{array}{l}18 \\
7 \\
1\end{array}$ & & $\begin{array}{l}4 \\
1\end{array}$ & $\begin{array}{l}2 \\
2 \\
2\end{array}$ & 2 & $\begin{array}{l}3 \\
1 \\
2\end{array}$ & 2 & & I & & $\begin{array}{l}1 \\
2\end{array}$ & & & & & & & & & $\begin{array}{l}84 \\
29 \\
14 \\
2\end{array}$ \\
\hline 50 & 234 & 39 & 115 & 35 & 58 & 76 & 43 & 8 & 32 & 4 & 46 & 4 & 6 & I & 3 & 9 & 5 & 2 & I & 1,306 \\
\hline
\end{tabular}

\begin{tabular}{|c|c|c|c|c|c|c|c|c|c|c|c|c|c|c|c|c|c|c|c|}
\hline 35 & 36 & 37 & 38 & 39 & 40 & 41 & 42 & 43 & 44 & 45 & 46 & 47 & 48 & 49 & 50 & 52 & 54 & 56 & Total \\
\hline $\begin{array}{l}28 \\
14 \\
27 \\
40 \\
27\end{array}$ & $\begin{array}{l}25 \\
19 \\
21 \\
21 \\
8\end{array}$ & $\begin{array}{l}16 \\
6 \\
12 \\
11 \\
8\end{array}$ & $\begin{array}{l}27 \\
20 \\
17 \\
31 \\
13\end{array}$ & $\begin{array}{l}8 \\
12 \\
9 \\
7 \\
3\end{array}$ & $\begin{array}{l}36 \\
37 \\
35 \\
39 \\
25\end{array}$ & $\begin{array}{l}4 \\
3 \\
7 \\
1 \\
1\end{array}$ & $\begin{array}{l}22 \\
7 \\
12 \\
12 \\
3\end{array}$ & $\begin{array}{l}5 \\
5 \\
1 \\
3 \\
1\end{array}$ & $\begin{array}{l}12 \\
3 \\
2 \\
4 \\
3\end{array}$ & $\begin{array}{l}10 \\
9 \\
7 \\
8 \\
2\end{array}$ & $\begin{array}{l}8 \\
2 \\
5 \\
4 \\
1\end{array}$ & I & $\begin{array}{l}5 \\
3 \\
2 \\
1\end{array}$ & I & $\begin{array}{l}5 \\
4 \\
1 \\
2\end{array}$ & 2 & I & I & $\begin{array}{l}285 \\
204 \\
244 \\
267 \\
176\end{array}$ \\
\hline $\begin{array}{l}12 \\
1 \\
1\end{array}$ & 5 & I & $\begin{array}{l}5 \\
2\end{array}$ & & 7 & $\begin{array}{l}3 \\
2 \\
1\end{array}$ & 1 & I & & 2 & & & & & I & & & & $\begin{array}{l}76 \\
37 \\
11 \\
5\end{array}$ \\
\hline 150 & 99 & 54 & 115 & 39 & 179 & 22 & 57 & 16 & 24 & 38 & 20 & 1 & 11 & 1 & 13 & 2 & 1 & $\mathrm{I}$ & 1,305 \\
\hline
\end{tabular}

would normally use the results of the disk-diffusion test when they encounter treatment failure, but many complain that the results of the disk-diffusion test are not useful for their decision-making regarding initial management. In our study, categorical agreements on KB tests and agar-dilution tests were both $80.9 \%$ for the two antibiotics, and the minor error for the KB tests was $19.1 \%$ for the two antibiotics, lessthan-acceptable performance rates (defined as $\geq 90 \%$ for categorical agreements and $\leq 7 \%$ for minor error). This agreement was lower than studies conducted by Mal et al (100\% agreement for ceftriaxone, 100 sensitive strains), ${ }^{17}$ Liu et al (91.3\% agreement for ceftriaxone and $89.6 \%$ for cefixime, 115 sensitive strains), ${ }^{18}$ Liao et al (100\% agreement for ceftriaxone, 163 sensitive strains), ${ }^{24}$ and Singh et al (95.9\% agreement for ceftriaxone, 283 sensitive strains and 12 insensitive strains). ${ }^{25}$ There are two possible reasons for the low categorical agreement. First, the comparative results in our study were collected from seven clinical sites, while the microbiology testing of the other three studies was conducted in a single laboratory. Indeed, categorical agreements for the two antibiotics between the two methods showed significant differences in different sites $(53.6 \%-98.9 \%$ for ceftriaxone, $67.1 \%-96.6 \%$ for cefixime). Second, the range of gonorrhea MIC in this study was larger and more comprehensive than other studies ${ }^{24,26}$ for ceftriaxone $(0.008-1 \mu \mathrm{g} / \mathrm{mL})$ and cefixime $(0.008-2 \mu \mathrm{g} / \mathrm{mL})$, including $90.1 \%$ sensitive strains and 9.9\% hyposensitive strains. The proportion of strains with decreased susceptibility to ceftriaxone in our study (9.9\%) was higher than the other studies (less than 5\%), which may partially account for the differences.

Pearson's correlation coefficients between KB tests and agar-dilution tests for ceftriaxone and cefixime in our study were lower than those of Liu et al $(-0.59$ and -0.67 , respectively, for ceftriaxone and cefixime). ${ }^{18,26}$ In our study, 100 insusceptible isolates for ceftriaxone were detected by agar dilution and also showed as susceptible on KB tests, and 91 isolates tested positive for cefixime. These results showed that the ability of KB tests to detect strains with decreased sensitivity to ceftriaxone or cefixime was extremely low. These false, sensitive results interpreted by KB tests will give clinicians the wrong suggestion for antibiotic use. This was a discouraging finding for clinical practice, because the 
results suggest that the $\mathrm{KB}$ test may not be an appropriate option for screening cephalosporin-resistant gonorrhoea strains in clinical practice, especially since the threat of reduced gonococcal susceptibility to ESCs is imminent in China. In our future surveillance program, we will further analyze the feasibility of the E-test method or the microdilution method ${ }^{23}$ for screening to detect cephalosporin gonorrhoea strains with decreased sensitivity in clinical practice in China. Limitations of this study include isolates from female gonorrhea patients accounting for only $6.6 \%$ of all samples, and $98.6 \%$ isolates being predominantly from the urethra in men and $100 \%$ from the cervix in women. The generalizability of the results may be limited, because the study contained very few isolates from cervical, rectal, or pharyngeal sites.

\section{Conclusion}

Although the KB test is relatively easy to carry out in clinical practice, its ability to detect cephalosporinresistant gonorrhoea strains is extremely low. This method is an inappropriate screening tool for cephalosporinresistant gonorrhoea strains in clinical practice in China.

\section{Acknowledgments}

The China Gonorrhoeae Resistance Surveillance Program is a national program coordinated by the Chinese National Center for Sexually Transmitted Disease under the leadership of the Commission of Health in China. The authors thank the collaborating sexually transmitted-infection clinics where this study took place and the participants of this study for their cooperation. This work was supported by the Chinese Academy of Medical Sciences Initiative for Innovative Medicine (grant 2016-I2M-3-021)), the National Science and Technology Major Project (2018ZX10101001-004-003), and the Guangdong Provincial Medical Science and Technology Program (B2018124).

\section{Disclosure}

The authors report no conflicts of interest in this work.

\section{References}

1. Newman L, Rowley J, Vander Hoorn S, et al. Global estimates of the prevalence and incidence of four curable sexually transmitted infections in 2012 based on systematic review and global reporting. PLoS One. 2015;10(12):e0143304. doi:10.1371/journal.pone.0143304

2. Brunham RC, Gottlieb SL, Paavonen J, Campion EW. Pelvic inflammatory disease. $N$ Engl J Med. 2015;372(21):2039-2048. doi:10.10 56/NEJMra1411426
3. Hook EW 3rd, Handsfield HH. Gonococcal infections in the adult. In: Holmes KK, Sparling PF, Mardh PA, Lemon SM, Stamm WE, Piot P, Wasserheit JN, eds. Sexually Transmitted Diseases. 3rd ed. New York: McGraw-Hill; 1999:451-466.

4. Cohen MS, Hoffman IF, Royce RA, et al. Reduction of concentration of HIV-1 in semen after treatment of urethritis: implications for prevention of sexual transmission of HIV-1. AIDSCAP Malawi Research Group. Lancet. 1997;349(9069):1868-1873. doi:10.1016/ S0140-6736(97)02190-9

5. Unemo M, Shafer WM. Antimicrobial resistance in Neisseria gonorrhoeae in the 21st century: past, evolution, and future. Clin Microbiol Rev. 2014;27:587-613.

6. Centers for Disease Control and Prevention (CDC). Cephalosporin susceptibility among Neisseria gonorrhoeae isolates: United States, 2000-2010. MMWR Morb Mortal Wkly Rep. 2011;60(26):873-877.

7. Yin Y-P, Han Y, Dai X-Q, et al. Susceptibility of Neisseria gonorrhoeae to azithromycin and ceftriaxone in China: a retrospective study of national surveillance data from 2013 to 2016. PLoS Med. 2018;15(2):e1002499. doi:10.1371/journal.pmed.1002499

8. Chen S-C, Yin Y-P, Chen X-S. Cephalosporin-resistant Neisseria gonorrhoeae clone, China. Emerg Infect Dis. 2018;24(4):804-806. doi:10.3201/eid2404.171817

9. Yokoi S, Deguchi T, Ozawa T, et al. Threat to cefixime treatment for gonorrhea. Emerg Infect Dis. 2007;13(8):1275-1277. doi:10.3201/ eid1308.060948

10. Ohnishi M, Golparian D, Shimuta K, et al. Is Neisseria gonorrhoeae initiating a future era of untreatable gonorrhea? Detailed characterization of the first strain with high-level resistance to ceftriaxone. Antimicrob Agents Chemother. 2011;55:3538-3545.

11. Unemo M, Golparian D, Potočnik M, et al. Treatment failure of pharyngeal gonorrhoea with internationally recommended first-line ceftriaxone verified in Slovenia, September 2011. Euro Surveill. 2012;17:20200.

12. Allen VG, Mitterni L, Seah C, et al. Neisseria gonorrhoeae treatment failure and susceptibility to cefixime in Toronto, Canada. JAMA. 2013;309(2):163-170. doi:10.1001/jama.2012.176575

13. Han Y, Yin Y, Dai X, et al. Widespread use of high-dose ceftriaxone therapy for uncomplicated gonorrhea without reported ceftriaxone treatment failure: results from 5 years of multicenter surveillance data in China. Clin Infect Dis. 2020;70(1):99-105. doi:10.1093/cid/ciz170

14. Clinical and Laboratory Standards Institute. Performance standards for antimicrobial susceptibility testing, 29th edition; 2018. Available from: https://clsi.org/standards/products/microbiology/documents/ m100/. Accessed May 27, 2019.

15. Lautenbach E, Patel JB, Bilker WB, et al. Extended-spectrum b-lactamase producing Escherichia coli and Klebsiella pneumoniae: risk factors for infection and impact of resistance on outcomes. Clin Infect Dis. 2001;32(8):1162-1171. doi:10.1086/319757

16. Bauer AW, Kirby WM, Sherris JC, et al. Antibiotic susceptibility testing by a standardized single disk method. Am J Clin Pathol. 1966;45(4_ts):493-496. doi:10.1093/ajcp/45.4_ts.493

17. Mal PB, Jabeen K, Farooqi J, et al. Antimicrobial susceptibility testing of Neisseria gonorrhoeae isolates in Pakistan by etest compared to calibrated dichotomous sensitivity and clinical laboratory standards institute disc diffusion techniques. BMC Microbiol. 2016;16(1):236. doi:10.1186/s12866-016-0707-6

18. Liu H, Taylor TH Jr, Pettus K, et al. Comparing the disk-diffusion and agar dilution tests for Neisseria gonorrhoeae antimicrobial susceptibility testing. Antimicrob Resist Infect Control. 2016;5(1):46. eCollection 2016. doi:10.1186/s13756-016-0148-x

19. U.S. Food and Drug Administration. Class II Special Controls Guidance Document: Antimicrobial Susceptibility Test (AST) Systems. U.S. Department of Health and Human Services Food and Drug Administration, Center for Devices and Radiological Health; 2007. Available from: http://www.fda.gov/MedicalDevices/ DeviceRegulationandGuidance/GuidanceDocuments/ucm080187. htm. Accessed June 19, 2020. 
20. Wu X, Qin X, Huang J, et al. Determining the in vitro susceptibility of Neisseria gonorrhoeae isolates from 8 cities in Guangdong Province through an improved microdilution method. Diagn Microbiol Infect Dis. 2018;92(4):325-331. doi:10.1016/j.diagmicrobio.2018.06.004

21. Wi T, Lahra MM, Ndowa F, et al. Antimicrobial resistance in Neisseria gonorrhoeae: global surveillance and a call for international collaborative action. PLoS Med. 2017;14(7):e1002344. doi:10.1371/ journal.pmed.1002344

22. Kirkcaldy RD, Harvey A, Papp JR, et al. Neisseria gonorrhoeae antimicrobial susceptibility surveillance - the gonococcal isolate surveillance project, 27 sites, United States, 2014. MMWR Surveill Summ. 2016;65(7):1-19. doi:10.15585/mmwr.ss6507a1

23. Cole MJ, Unemo M, Hoffmann S, et al. The European gonococcal antimicrobial surveillance programme, 2009. Euro Surveill. 2011;16:19995.
24. Liao CH, Lai CC, Hsu MS, et al. Antimicrobial susceptibility of Neisseria gonorrhoeae isolates determined by the agar dilution, disk diffusion and Etest methods: comparison of results using GC agar and chocolate agar. Int J Antimicrob Agents. 2010;35(5):457-460. doi:10.1016/j.ijantimicag.2010.01.007

25. Singh V, Bala M, Kakran M, et al. Comparative assessment of CDS, CLSI disc diffusion and Etest techniques for antimicrobial susceptibility testing of Neisseria gonorrhoeae: a 6-year study. BMJ Open. 2012;2(4):e000969. doi:10.1136/bmjopen-2012-000969

26. Liu H, Taylor TH Jr, Pettus K, et al. Assessment of Etest as an alternative to agar dilution for antimicrobial susceptibility testing of Neisseria gonorrhoeae. J Clin Microbiol. 2014;52(5):1435-1440. doi:10.1128/JCM.02131-13

\section{Publish your work in this journal}

Infection and Drug Resistance is an international, peer-reviewed openaccess journal that focuses on the optimal treatment of infection (bacterial, fungal and viral) and the development and institution of preventive strategies to minimize the development and spread of resistance. The journal is specifically concerned with the epidemiology of antibiotic resistance and the mechanisms of resistance development and diffusion in both hospitals and the community. The manuscript management system is completely online and includes a very quick and fair peerreview system, which is all easy to use. Visit http://www.dovepress.com/ testimonials.php to read real quotes from published authors. 